\title{
Diversity, abundance, and host relationships of avian malaria and related haemosporidians in New Mexico pine forests
}

Rosario A. Marroquin-Flores ${ }^{1}$, Jessie L. Williamson ${ }^{1}$, Andrea N. Chavez ${ }^{1,2}$, Selina M. Bauernfeind ${ }^{1}$, Matthew

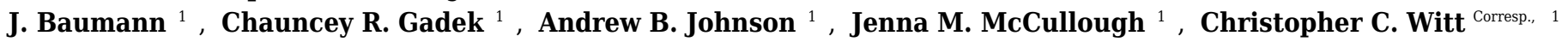
, Lisa N. Barrow ${ }^{\text {Corresp. } 1}$

${ }^{1}$ Museum of Southwestern Biology and Department of Biology, University of New Mexico, Albuquerque, NM, United States

2 Bureau of Land Management Rio Puerco Field Office, Rio Puerco, NM, United States

Corresponding Authors: Christopher C. Witt, Lisa N. Barrow

Email address: cwitt@unm.edu, Inbarrow@unm.edu

Avian malaria and related haemosporidian parasites (genera Haemoproteus, Plasmodium, and Leucocytozoon) affect bird demography, species range limits, and community structure, yet they remain unsurveyed in most bird communities and populations. We conducted a community-level survey of these vector-transmitted parasites in New Mexico, USA, to describe their diversity, abundance, and host associations. We focused on the breeding-bird community in the transition zone between piñon-juniper woodland and ponderosa pine forests (elevational range: 2150-2460 meters). We screened 186 birds representing 49 species using both standard PCR and microscopy techniques to detect infections of all three avian haemosporidian genera. We detected infections in 68 out of 186 birds (36.6\%), the highest proportion of which were infected with Haemoproteus (20.9\%), followed by Leucocytozoon (13.4\%), then Plasmodium (8.0\%). We sequenced mtDNA for 77 infections representing 43 haplotypes (25 Haemoproteus, 12 Leucocytozoon, 6 Plasmodium). When compared to all previously known haplotypes in the MalAvi and GenBank databases, 63\% (27) of the haplotypes we recovered were novel. We found evidence for host specificity at the avian clade and species level, but this specificity was variable among parasite genera, in that Haemoproteus and Leucocytozoon were each restricted to three avian groups (out of six), while Plasmodium occurred in all groups except non-passerines. We found striking variation in infection rate among host species, with nearly universal infection among vireos and no infection among nuthatches. Using rarefaction and extrapolation, we estimated the total avian haemosporidian diversity to be 70 haplotypes (95\% Cl: 43-98); thus, we may have already sampled $\sim 60 \%$ of the diversity of avian haemosporidians in New Mexico pine forests. It is possible that future studies will find higher diversity in microhabitats or host species that are under-sampled or unsampled in the present study. Fortunately, this study is fully extendable via voucher specimens, frozen tissues, blood smears, parasite images, and documentation provided in open-access 
databases (MalAvi, GenBank, and ARCTOS). 
Diversity, abundance, and host relationships of avian malaria and related haemosporidians

in New Mexico pine forests

Short title: Avian malaria diversity in New Mexico

Rosario A. Marroquin-Flores ${ }^{1}$, Jessie L. Williamson ${ }^{1}$, Andrea N. Chavez ${ }^{1,2}$, Selina M.

Bauernfeind $^{1}$, Matthew J. Baumann ${ }^{1}$, Chauncey R. Gadek ${ }^{1}$, Andrew B. Johnson ${ }^{1}$, Jenna M.

McCullough $^{1}$, Christopher C. Witt ${ }^{1}$, Lisa N. Barrow ${ }^{1}$

${ }^{1}$ Museum of Southwestern Biology and Department of Biology, University of New Mexico, Albuquerque, New Mexico, USA

${ }^{2}$ Bureau of Land Management Rio Puerco Field Office, Rio Puerco, New Mexico, USA

Corresponding authors:

Lisa N. Barrow (lnbarrow@unm.edu), Christopher C. Witt (cwitt@unm.edu) 


\section{Abstract}

2 Avian malaria and related haemosporidian parasites (genera Haemoproteus, Plasmodium, and

3 Leucocytozoon) affect bird demography, species range limits, and community structure, yet they

4 remain unsurveyed in most bird communities and populations. We conducted a community-level

5 survey of these vector-transmitted parasites in New Mexico, USA, to describe their diversity,

6 abundance, and host associations. We focused on the breeding-bird community in the transition

7 zone between piñon-juniper woodland and ponderosa pine forests (elevational range: 2150-2460

8 meters). We screened 186 birds representing 49 species using both standard PCR and

9 microscopy techniques to detect infections of all three avian haemosporidian genera. We

10 detected infections in 68 out of 186 birds (36.6\%), the highest proportion of which were infected

11 with Haemoproteus (20.9\%), followed by Leucocytozoon (13.4\%), then Plasmodium (8.0\%). We

12 sequenced mtDNA for 77 infections representing 43 haplotypes (25 Haemoproteus, 12

13 Leucocytozoon, 6 Plasmodium). When compared to all previously known haplotypes in the

14 MalAvi and GenBank databases, 63\% (27) of the haplotypes we recovered were novel. We

15 found evidence for host specificity at the avian clade and species level, but this specificity was

16 variable among parasite genera, in that Haemoproteus and Leucocytozoon were each restricted to

17 three avian groups (out of six), while Plasmodium occurred in all groups except non-passerines.

18 We found striking variation in infection rate among host species, with nearly universal infection

19 among vireos and no infection among nuthatches. Using rarefaction and extrapolation, we

20 estimated the total avian haemosporidian diversity to be 70 haplotypes (95\% CI: 43-98); thus,

21 we may have already sampled $\sim 60 \%$ of the diversity of avian haemosporidians in New Mexico

22 pine forests. It is possible that future studies will find higher diversity in microhabitats or host

23 species that are under-sampled or unsampled in the present study. Fortunately, this study is fully 
24 extendable via voucher specimens, frozen tissues, blood smears, parasite images, and 25 documentation provided in open-access databases (MalAvi, GenBank, and ARCTOS). 


\section{Introduction}

Parasites are influential components of biotic communities, yet the vast majority of parasite diversity remains undescribed (Dobson et al., 2008; Poulin, 2014). A striking example is provided by the haemosporidian parasites (Protozoa: Apicomplexa: Haemosporida) that infect primates, rodents, bats, lizards, and birds. Avian malaria and related haemosporidians of the genera Haemoproteus (including Parahaemoproteus), Plasmodium, and Leucocytozoon are known to affect bird community structure (Atkinson et al., 2013; Kulma et al., 2013; Clark, Clegg \& Lima, 2014), immune function (Atkinson et al., 2001; Beadell et al., 2007), telomere length and senescence (Asghar et al., 2015), survivorship (Atkinson et al., 2000), and fecundity (Knowles, Palinauskas \& Sheldon, 2010). Over 200 avian haemosporidian species have been described based on morphology (Valkiūnas, 2005), but mitochondrial (mtDNA) sequences have revealed that at least one order of magnitude higher diversity exists (Bensch, Hellgren \& PérezTris, 2009; Clark, Clegg \& Lima, 2014). Nearly two decades since the introduction of mtDNA 'barcode' survey methods (Bensch et al., 2000), many geographic regions and the vast majority of avian populations remain unsurveyed for haemosporidians. New community-level surveys will be critical to understanding their diversity, biogeography, and coevolutionary dynamics.

The need for new descriptive data on avian haemosporidian communities is vital, particularly in under-sampled regions and habitats, for several reasons. Interacting bird, dipteran, and avian haemosporidian species underlie the disease transmission cycle (Valkiūnas, 2005; LaPointe, Goff \& Atkinson, 2010), and these species are likely to be susceptible to range shifts driven by climate warming. This situation creates the potential for novel host-parasite interactions. When naïve hosts encounter novel haemosporidian parasites, the consequences can be severe, as illustrated by the decimation of native Hawaiian honeycreepers after the 
49 introduction of Plasmodium relictum (Warner, 1968; van Riper et al., 1986; Atkinson et al., 50 2000). Furthermore, increased temperatures can result in multiple reproductive cycles for the

51 dipteran definitive hosts (Robinet \& Roques, 2010), potentially causing increased infection risk

52 or parasitemia, with negative consequences for bird population growth (Scott et al., 1983; Brown

53 et al., 2001; Garamszegi, 2011). Increased contact between hosts and parasites may also facilitate

54 host-switching, which appears to be a common mode of diversification in this group (Ricklefs \&

55 Fallon, 2002; Galen \& Witt, 2014; Ricklefs et al., 2014). Descriptions of avian haemosporidian

56 communities will elucidate the ecological niches, host relationships, and host-switching potential

57 of parasite lineages, providing information that will be critical for wildlife management and will

58 provide a basis for predicting climate change impacts.

59 The southwestern United States, in particular, is mostly unsurveyed and is likely to

60 harbor a distinct avian haemosporidian assemblage, in part because its arid environment imposes

61 challenges for the dipteran definitive hosts that serve as vectors (Yohannes et al., 2005; Lachish

62 et al., 2011). The few previous community-level surveys of avian haemosporidian parasites in

63 western North America have been conducted in California (Martinsen et al., 2008; Walther et al.,

64 2016) and Alaska (Loiseau et al., 2012; Oakgrove et al., 2014). Here we report on the first

65 community-level avian haemosporidian survey in New Mexico, USA. New Mexico's arid

66 climate and broad elevation gradients provide a compelling and untapped system in which to

67 investigate avian haemosporidian diversity and ecology. We focus specifically on the breeding-

68 season community in the elevational zone between $2150-2460$ meters, which is characterized by

69 the transition from forests dominated by piñon pine to those dominated by ponderosa pine. Our

70 objectives were: (1) To compare infection rates for each of the three avian haemosporidian

71 genera (Haemoproteus, Plasmodium, and Leucocytozoon) among a suite of breeding bird species 
72 using microscopy and mtDNA; (2) To describe associations between avian haemosporidian

73 haplotypes and their host species in a phylogenetic context; (3) To evaluate haplotype-richness

74 ( $\alpha$-diversity) of the avian haemosporidian community in a previously unsurveyed region and

75 habitat, including the proportion of lineages that are novel (never found in previous surveys).

76 The survey results that we report are fully extendable via voucher specimens, frozen tissues,

77 blood smears, parasite images, and documentation in open-access databases (MalAvi, GenBank, 78 and ARCTOS).

Methods

\section{Field Sampling}

82 We conducted fieldwork during June and July 2016 at three sites in northern New Mexico within

83 the jurisdiction of the Rio Puerco Field Office of the Bureau of Land Management (BLM), an

84 agency within the United States Department of Interior. The three sites included: (1) Mesa

85 Chivato (McKinley and Sandoval Counties; on the northern flank of Mt. Taylor); (2) El Malpais

86 National Conservation Area (Cibola County; on the southern side of the Zuni Mountains); and

87 (3) Elk Springs (Sandoval County; on the western slope of the Jemez Mountains; Fig. 1).

88 Sampling was conducted within a narrow elevational band (2150-2460 m) at the upper

89 elevational extent of piñon-juniper woodland, where it transitions to ponderosa pine forest. These

90 pine-dominated habitats were interspersed with patches of grassland and occasional Gambel oak,

91 Douglas fir, or aspen. Permanent water was scarce in the sampled habitats, consisting of a tiny,

92 spring-fed creek in the Elk Springs site, a natural spring (Ojo de los Indios) that has been

93 developed in Mesa Chivato, and a few widely-dispersed watering troughs and earthen tanks for

94 cattle or wildlife in Mesa Chivato and El Malpais National Conservation Area. 
We focused on the breeding-season community in order to characterize locally-

96 transmitted parasites. Sampling during the breeding season may also maximize detection because

97 breeding birds frequently exhibit relapses of latent avian malaria infections (Applegate, 1970;

98 Valkiūnas et al., 2004; Garvin \& Schoech, 2006), possibly associated with increases in

99 glucocorticoid stress hormones (Romero, 2002). Blood smears were prepared at the time of

100 collection and were later fixed and stained in the lab (details below). Whole avian specimens

101 were collected by mist-net or shotgun, preserved on dry ice, and transported to the Museum of

102 Southwestern Biology (MSB) at the University of New Mexico for specimen preparation and

103 preservation of tissues for genetic analysis. All samples were collected under Institutional

104 Animal Care and Use Protocol 16-200406-MC and appropriate state and federal scientific

105 collecting permits (New Mexico Department of Game and Fish Authorization Number 3217;

106 U.S. Fish and Wildlife Permit Number MB094297-0). Complete details on each specimen,

107 including precise locality, collection method, and necropsy data are available in Table S1 and its

108 embedded links to the ARCTOS database. Additionally, all novel haemosporidian haplotypes,

109 host species infected, and occurrence sites were documented in GenBank, the MalAvi database

110 (Bensch, Hellgren \& Pérez-Tris, 2009) and in Tables S1-S2.

\section{Genetic data collection}

113 We extracted genomic DNA from frozen pectoral muscle tissue of 186 avian specimens using a

114 QIAGEN DNeasy Blood and Tissue Kit, following the manufacturer's protocol. To maximize

115 detection of different parasite genera, we used three nested polymerase chain reaction (PCR)

116 protocols to amplify a 478 base pair fragment of cytochrome b (cytb) in the haemosporidian

117 mitochondrial genome, as described by Hellgren, Waldenström \& Bensch (2004) and 
118 Waldenström et al. (2004). We used the outer primer pairs HaemNFI/HaemNR3 and

119 HaemNF/HaemNR2 with the nested primer pair HaemF/HaemR2 to screen for Haemoproteus

120 and Plasmodium. We used the outer primer pair HaemNFI/HaemNR3 with the nested primer pair

121 HaemFL/HaemR2L to screen for Leucocytozoon. Each outer PCR contained 1.25 U AmpliTaq

122 Gold DNA Polymerase (Applied Biosystems), 1X PCR Buffer II, $2.5 \mathrm{mM} \mathrm{MgCl}, 0.2 \mathrm{mM}$

$123 \mathrm{dNTP}, 0.5 \mu \mathrm{M}$ each primer, and $20 \mathrm{ng}$ template DNA in a total reaction volume of $25 \mu \mathrm{l}$. The

124 thermal profile of this reaction was modified following Galen \& Witt (2014) and consisted of an

125 initial 8-min denaturation step at $95^{\circ} \mathrm{C}$, followed by 20 cycles of $94^{\circ} \mathrm{C}$ for $30 \mathrm{sec}, 50^{\circ} \mathrm{C}$ for 30

$126 \mathrm{sec}$, and $72^{\circ} \mathrm{C}$ for $45 \mathrm{sec}$, with a final 10 -min extension at $72^{\circ} \mathrm{C}$. The nested PCR used the outer

127 PCR product as the template (1 $\mu \mathrm{l}$ for Haemoproteus and Plasmodium; $2 \mu 1$ for Leucocytozoon).

128 Reaction conditions were the same for nested PCR except the number of cycles was increased to

129 35. Negative and positive controls were included in each PCR reaction to check for

130 contamination and to verify successful DNA amplification. All PCR reactions were visualized on

$1312 \%$ agarose gels using SYBR Safe Gel Stain (Invitrogen) to identify positive samples and verify

132 the presence of PCR product of the expected length. All successful amplifications were purified

133 using ExoSap-IT (Affymetrix, Inc.) and sequenced in both directions using dye terminator cycle

134 sequencing on an ABI 3130 sequencer at the UNM Molecular Biology Core Facility.

\section{Microscopic examination}

137 Blood smears were air dried in the field and, within six months, were fixed using absolute

138 methanol and stained for 50 minutes with phosphate-buffered Giemsa solution (7.0 pH). We

139 examined each blood smear for evidence of haemosporidian blood parasites using either a Leica

140 DM5000 B or a Nikon Labophot-2 light microscope, following identification protocol described 
141 by Valkiūnas (2005). We scanned at least 10,000 erythrocytes in all viable smears at $1000 \mathrm{X}$

142 magnification using an oil immersion lens. We did not attempt to identify gametocytes to

143 morphospecies; rather, we took digital photographs to archive in the ARCTOS database. We re-

144 screened $76(45 \%)$ of the blood smears to confirm negative or positive identifications after an

145 initial comparison with PCR results.

147 Genetic data analysis

148 Parasite sequences were edited and aligned using the default alignment algorithm in Geneious

149 version 8.0 (Biomatters Ltd; Kearse et al., 2012). We compared our sequences to previously

150 sequenced infections in the public databases GenBank (National Center for Biotechnology

151 Information, U.S. National Library of Medicine) and MalAvi (Bensch, Hellgren \& Pérez-Tris,

152 2009) using the Basic Local Alignment Search Tool (BLAST). We used the closest match to

153 determine the parasite genus for each haplotype. Studies have indicated that avian

154 haemosporidian sequences differing by a single base pair can differ in host association and in

155 transmission (Bensch, Hellgren \& Pérez-Tris, 2009). We therefore characterized parasite

156 haplotypes differing by one or more base pairs from existing sequences in the GenBank and

157 MalAvi databases as novel and named them following MalAvi naming conventions (first three

158 letters of the genus and species of the first bird host species from which the haplotype was

159 sequenced, followed by a haplotype number for that bird species). Some authors have suggested

160 combining haplotypes into 'lineages' based on a 1\% divergence rule (Outlaw \& Ricklefs, 2014)

161 and considering geographic distributions and hosts infected (Svensson-Coelho et al., 2013). By

162 these definitions, 'lineages' are considered to represent putative species; however, species limits

163 are difficult to determine with the data at hand. In this study, we tentatively treat each haplotype 
164 as a unique lineage; additional sampling will be required to determine whether some of these

165 closely related haplotype groups may represent segregating variants within single populations.

166 In addition to reporting the proportion of infected birds, we reported the combined

167 infection rate, defined as the number of infections detected divided by the number of birds

168 screened. The latter metric accounts for the total number of infections in a host population,

169 including multiple infections within a single host. We defined co-infection as testing PCR

170 positive for more than one genus of haemosporidian parasite (i.e. possessing both Leucocytozoon

171 and Haemoproteus/Plasmodium), or testing positive for more than one haplotype within a

172 parasite genus (i.e. two distinct Haemoproteus or Plasmodium haplotypes), either in separate

173 nested PCR reactions or by presence of double peaks in sequence chromatograms.

174 We estimated the phylogenetic relationships among New Mexico haemosporidian

175 parasites based on cytb using maximum likelihood in RAxML version 8.2 (Stamatakis, 2014).

176 Given the modest size of the dataset, we analyzed all codon positions as a single partition. We

177 used the GTR + G model of nucleotide substitution and conducted a rapid bootstrap analysis with

1781000 bootstrap replicates, after which we searched for the best-scoring maximum-likelihood tree.

179 We did not specify an outgroup for the ML analysis and instead rooted the tree at the

180 Leucocytozoon clade based on the relationships for Haemosporida determined using several loci

181 and taxa (Borner et al. 2016). We generated a phylogenetic tree for the avian species sampled

182 using BirdTree.org, which uses calibrated backbone trees of well-supported avian clades and

183 generates trees for all bird species by partially constraining them to their respective clade

184 (expanded methods in Jetz et al., 2012, 2014). We used the phylogeny subsets tool to download a

185 tree including only the species we sampled from the 'Ericson All Species' source of trees

186 (Ericson et al., 2006). 
Estimates of lineage diversity

189 We used EstimateS version 9.1.0 (Colwell, 2013) to generate an estimate of undiscovered

190 lineage diversity present in northern New Mexico avian haemosporidian communities. This

191 approach estimates species richness in a community based on rarefaction and extrapolation of

192 reference samples (Colwell et al., 2012). We used counts for each parasite haplotype as

193 individual-based abundance data regardless of host species identity, which should result in a

194 conservative estimate of species richness. Rarefaction was conducted with 100 randomizations

195 and the rarefaction curve was extrapolated with unconditional $95 \%$ confidence intervals to a total

196 of 400 individuals, at which point the species richness curve reached an asymptote.

197

198 Results

199 Parasite abundance

200 We collected 186 individuals from 49 species and representing 19 families of New Mexico birds

201 (Table S1). Twenty-six species tested positive for one or more of the three genera of avian

202 haemosporidian parasites. In total, 65 out of 186 birds $(34.9 \%)$ were infected based on PCR.

203 These include 39 birds infected with one or more lineages of Haemoproteus (20.9\%), 15 birds

204 infected with Plasmodium (8.0\%), and 25 birds infected with Leucocytozoon (13.4\%). Two

205 additional individuals tested positive for either Haemoproteus or Plasmodium in the PCR

206 screening, but we were unable to identify these lineages to genus because of poor sequence

207 quality. Combined infection rates were variable among parasite genera, as well as among host

208 clades and host species (Fig. 2). A total of 18 (9.7\%) individuals were co-infected, including two

209 mixed infections comprised of Leucocytozoon with Plasmodium, 12 of Leucocytozoon with 
210 Haemoproteus, two of Haemoproteus with Haemoproteus, and one of Plasmodium with

\section{Plasmodium.}

212 We completed microscopic examination for 168 individuals $(90 \%)$ that had blood smears

213 of adequate quality. We detected evidence of positive haemosporidian infection in $43(25.6 \%)$ of

214 the individuals screened. The rate of detection with PCR was higher than microscopy (Table 1).

215 In 21 cases, PCR was positive with a negative microscopy result, and in three cases, microscopy

216 was positive with a negative PCR result. Parasitemia (defined as the proportion of red blood cells

217 infected out of 10,000 ) was $<1 \%$ for the majority of slides examined. The highest level of

218 infection was in an individual of Empidonax oberholseri (Tyrannidae) with $\sim 2 \%$ of red blood

219 cells infected. Combining both PCR and microscopy results, 68 of 186 (36.6\%) birds were

220 infected.

221

222 Parasite diversity

223 We identified a total of 83 positive PCR infections, and obtained unambiguous sequences from

22477 of them. Six sequences of poor quality were excluded from the parasite phylogeny and

225 lineage diversity analyses because they could not be assigned to a haplotype. Four of these

226 excluded sequences were positively identified as Leucocytozoon by the primer pair used, and two

227 were either Haemoproteus or Plasmodium. These infections were included for the calculation of

228 overall and Leucocytozoon infection rates. The 77 sequenced infections consisted of 43 distinct

229 parasite haplotypes, including 25 Haemoproteus, six Plasmodium, and 12 Leucocytozoon

230 haplotypes (Fig. 2; Table S2). Based on published sequences in the MalAvi and GenBank

231 databases, 27 haplotypes (63\%) identified were novel, which consisted of 17 novel haplotypes

232 for Haemoproteus (meaning 68\% of the haplotypes we found for the genus were novel), two for 
233 Plasmodium (33\%), and eight for Leucocytozoon (67\%). Additionally, we found evidence of

234 infection in four juvenile birds; one with Leucocytozoon and two with novel Haemoproteus

235 lineages, providing evidence for local transmission (Table S1). Sequences generated for each

236 haplotype in this study are available on MalAvi and GenBank (Tables S1-S2; GenBank

237 accession numbers: MF077648-MF077690).

238

239 Parasite phylogeny and host associations

240 The parasite phylogeny indicated strong support for the sister group relationship between avian

241 Haemoproteus and Plasmodium (bootstrap value $=100$ ). We recovered monophyletic

242 relationships for each genus with strong to moderate support (bootstrap values: 100 for

243 Leucocytozoon, 85 for Haemoproteus, 67 for Plasmodium). We found evidence for associations

244 between host clades and parasite genera. All Haemoproteus haplotypes were restricted to three

245 avian clades: Passerides clade 1b, Corvides, and Suboscines (Fig. 2). Similarly, all

246 Leucocytozoon haplotypes were restricted to Passerides clade 1b, Passerides clade 2, and

247 Corvides. Plasmodium infections occurred in all avian clades or groups sampled except non-

248 passerines. We found no infections in non-passerine species, which may be due to low sample

249 size $(\mathrm{n}=8)$. Although node-support values were modest, some monophyletic Haemoproteus

250 groups appear to be restricted to single avian clades (Fig. 2). Notably, the clade containing

251 VIRPLU04 to VIGIL07 included 14 infections, all of which we recovered from avian hosts in

252 the genus Vireo.

253 
254 Estimates of lineage diversity

255 A rarefaction curve generated in EstimateS using the 77 infections and 43 haplotypes identified 256 suggested that the total haplotype richness is $\sim 70$ (95\% CI: 43-98; Fig. 3). According to this

257 method, we have identified $\sim 60 \%$ of the lineage diversity present at these sites, and sampling a 258 total of $\sim 240$ infections should be sufficient to capture $>95 \%$ of the lineage diversity in this 259 avian haemosporidian community. Based on our PCR-derived infection rate of $34.9 \%$, this 260 projection suggests we will need to screen $\sim 690$ birds, or $\sim 500$ additional samples to adequately

261 characterize the avian haemosporidian community of New Mexico pine forests. This estimate 262 should be regarded as a conservative minimum estimate of the sampling needed, as explained 263 below.

265 Discussion

266 Haemosporidian abundance in New Mexico pine forest breeding bird communities

267 We detected high levels of infection in the first community-wide survey of blood parasites in

268 New Mexico breeding birds, with over one third (36.6\%) of individuals infected with at least one 269 of the three parasite genera. This level of infection is comparable to community surveys in other 270 parts of the U.S. including California (39.8\% of 399 birds; Walther et al., 2016), Alaska (53\% of 271903 birds; Oakgrove et al., 2014), and Missouri (38.6\% of 757 birds; Ricklefs et al., 2005).

272 Community-level surveys in other parts of the world vary widely in avian haemosporidian 273 infection rates, from 17.4\% of 2661 birds in Brazil (excludes Leucocytozoon; Fecchio et al., 274 2017), to 79.1\% of 532 birds in east Africa (Lutz et al., 2015). In our New Mexico study, 275 Haemoproteus was the most abundant parasite genus (20.9\% of birds infected), followed by 276 Leucocytozoon (13.4\%), then Plasmodium (8.0\%). This generic composition was strikingly 
277 different from that found by some previous studies in western North America. For example,

278 Walther et al. (2016) found much higher Plasmodium infection rates compared to the other two

279 genera in a California songbird community, and Oakgrove et al. (2014) found Leucocytozoon to

280 be the most abundant genus in an Alaska survey. The time of year in which samples were

281 collected may have contributed to these patterns. For example, Walther et al., (2016) sampled

282 from April to January, while we focused our sampling efforts on the breeding season (June and

283 July). Haemoproteus may be easier to detect by PCR over short timeframes because relapses are

284 generally longer in Haemoproteus infections compared to Plasmodium (Valkiunas, 2005).

285 Another factor to consider is the relative absence of standing water in ponderosa pine forest and 286 piñon-juniper woodland habitats and how differences in vector ecology may contribute to these

287 patterns. For instance, simuliid black flies that transmit Leucocytozoon parasites commonly lay

288 eggs in running water (Adler, Currie \& Wood, 2004). Interestingly, Elk Springs, the site with a

289 spring-fed creek, had a higher Leucocytozoon infection rate (32\%) compared to Mesa Chivato

290 (13\%) and El Malpais National Conservation Area (10\%), but this pattern remains to be

291 confirmed with additional sampling.

292 The variation in infection rate that we detected among host species suggests intriguing

293 avenues for further investigation. We uncovered extremely high infection and co-infection rates

294 in two Vireo species, Vireo gilvus and V.plumbeus. Of 13 individuals collected, 12 (92\%) were

295 positive for either Haemoproteus or Leucocytozoon, and eight (61.5\%) were co-infected. Walther

296 et al. (2016) also identified high infection rates in Vireo gilvus $(\mathrm{n}=11)$ and identified $V$. gilvus as

297 the only study species to be co-infected with more than three parasite lineages. The high rates of

298 infection and co-infection indicate that Vireo species will be important to investigate as potential

299 reservoirs for Haemoproteus and Leucocytozoon parasites (e.g., Möens et al., 2016). In contrast, 
300 the three species of nuthatches (Sitta pygmaea, S. canadensis, S. carolinensis) in our survey were

301 completely uninfected $(n=12)$. It is possible that immune function or ecological characteristics

302 minimize infection in these species. For example, nuthatches are cavity-nesters, a characteristic

303 that is hypothesized to reduce exposure time to vectors and result in lower infection rates

304 (Fecchio et al., 2011; Svensson-Coelho et al., 2013; Lutz et al., 2015; Medeiros et al., 2015).

305 The number of positive infections we detected with PCR differed somewhat from

306 microscopy results, consistent with previous studies that have compared the two methods

307 (Valkiūnas et al., 2008; Möens et al., 2016). Differences between PCR and microscopy detection

308 are expected for at least three reasons. First, PCR can identify a positive infection with fewer

309 than a single parasite per one million host cells (Hellgren, Waldenström \& Bensch, 2004),

310 infections that are unlikely to be detected using standard microscopic examinations of $10,000-$

311 100,000 cells (Atkinson et al., 2000). Second, it is conceivable that infections detected by PCR

312 may be abortive infections, which would not develop into gametocytes in the blood stream

313 (Valkiūnas et al., 2013). Third, detection by PCR appears to be sensitive to tissue type, with

314 higher detection probability for heart, liver, or pectoral muscle tissue compared to blood

315 (Svensson-Coelho et al., 2016). We sampled pectoral muscle tissue, for which Svensson-Coelho

316 et al. (2016) found fewer false negatives compared to other tissue types, although in that study,

317 no tissue type detected every infection that was detected by at least one of the four tissue types.

319 Novel parasite diversity and apparent host clade associations

320 Our survey revealed high diversity of avian haemosporidian parasites in northern New Mexico

321 including several novel lineages. Of the 43 haplotypes we sampled, 16 have previously been

322 identified and published in MalAvi or GenBank. Nine of these have only been documented in the 
323 U.S., six of which have only been identified within the western U.S., suggesting restricted

324 geographical ranges within continental North America for at least some lineages. Haemoproteus

325 was the most diverse lineage in our study with 25 haplotypes identified, 17 of which were novel.

326 Likewise, several studies in other parts of the world including Asia, Europe, and sub-Saharan

327 Africa have documented higher lineage diversity in Haemoproteus compared to Plasmodium

328 (reviewed in Clark, Clegg \& Lima, 2014). Other surveys have found either Plasmodium

329 (California: Walther et al., 2016; South America: Svensson-Coelho et al., 2013; Fecchio et al.,

330 2017) or Leucocytozoon (Alaska: Oakgrove et al., 2014; eastern Africa: Lutz et al., 2015) to have

331 higher diversity compared to other genera. We found more novel lineages ( 27 total, or $63 \%$ ) than

332 similar community-level surveys in California (40\% novel; Walther et al., 2016) and Alaska

333 (49\% novel; Oakgrove et al., 2014) despite having a much smaller sample size thus far. In this

334 study, we sampled 186 birds compared to 399 birds (Walther et al., 2016) and 913 birds

335 (Oakgrove et al., 2014), and all three surveys sampled a similar number of host species (46-49).

336 The apparent host breadth and geographic range of the lineages we sampled provides

337 evidence for some generalist parasites, mostly within Plasmodium. For example, LAIRI01 was

338 found in four different avian clades in our study, and has previously been reported in the

339 Philippines, Ecuador, and Mexico (Silva-Iturriza, Ketmaier \& Tiedemann, 2012; Levin et al.,

340 2013). We found one occurrence of WW3, which is distributed across Africa, Europe, and other

341 parts of the U.S. (Waldenström et al., 2002; Bensch \& Åkesson, 2003; Hellgren et al., 2007).

342 One Haemoproteus lineage, SIAMEX01, also appears to be wide-ranging across the U.S. and

343 has been identified in several avian hosts (Ricklefs \& Fallon, 2002; Levin et al., 2013). The

344 majority of avian haemosporidian lineages found in our study, however, seem to be host specific

345 at the species or clade level. One example includes the six Haemoproteus and two 
346 Leucocytozoon lineages that were specific to Vireo species in our study, although one of these

347 haplotypes, TROAED12, was first described from a different host species, the house wren

348 (Troglodytes aedon; Galen \& Witt, 2014). Three of the vireo-specific lineages in our study

349 (VIGIL02, VIGIL05, and VIGIL07) were also identified in Vireo species in California (Walther

350 et al., 2016). Interestingly, a clade of haemosporidians specific to two eastern Vireo species was

351 identified by Ricklefs et al., (2005), but those haplotypes cannot be directly compared at present

352 because a different portion of $c y t b$ was sequenced. Among the major host clades, lineage

353 diversity was highest for Passerides clade $1 \mathrm{~b}$ and Corvides. Most Haemoproteus and

354 Leucocytozoon lineages were sampled from a single avian host clade, but additional sampling is

355 needed to confirm the patterns of host specificity in New Mexico pine forest breeding bird

356 communities.

357 Our estimates of total avian haemosporidian lineage diversity indicate that a substantial

358 number of haplotypes, $\sim 25$, remain to be sampled in these communities; this is likely to be an

359 underestimate. Although there was evidence of host specificity, we could not account for host-

360 species identity in our rarefaction procedure in EstimateS because sample sizes for individual

361 host species were small and biased towards common species. Considering the preponderance of

362 unsampled and under-sampled bird species in the community, the avian haemosporidian

363 diversity in New Mexico pine forests is likely much higher than the estimate presented here. For

364 the same reasons, uneven sampling among the three sites may have exacerbated our

365 underestimation of diversity, particularly if there is species-turnover among mountain ranges.

366

367 Conclusions 
368 We uncovered a diverse community of avian haemosporidian parasites in New Mexico pine

369 forests, with the majority of infections representing novel mtDNA haplotypes. We found

370 evidence for host-specificity at the level of avian species and clades. There was also striking

371 variation in infection rates among avian species and clades, exemplified by near universal

372 infection of vireos and absence of infection in nuthatches. This study underscores the need for

373 further sampling in southwestern North America in order to discover the diversity of ecologically

374 important parasites that are interacting with birds. Follow-up studies should extend on the open-

375 data provided here to test our extrapolation of the total avian haemosporidian haplotype

376 diversity, and to determine the extent to which the avian haemosporidian community varies

377 among neighboring 'sky island' mountain ranges or at elevations above or below the zone

378 sampled here.

379

380 Acknowledgements

381 We thank Michael J. Andersen, Celina Aguilar, Becky Bixby, Sara V. Brant, Mariel Campbell,

382 Spencer Galen, and Xena Mapel for support; George Rosenberg of the Molecular Biology Core

383 Facility at UNM for assistance with sequencing; the U.S. Fish and Wildlife Service and New

384 Mexico Department of Game and Fish for providing permits; the Bureau of Land Management

385 for logistical support and site access; and Xi Huang and two anonymous reviewers for comments

386 on the manuscript. 
387

388

389

390

391

392

393

394

395

396

397

398

399

400

401

402

403

404

405

406

407

408

409

410

411

412

413

414

415

416

417

418

419

420

421

422

423

424

425

426

427

428

429

430

431

\section{References}

Adler PH., Currie DC., Wood DM. 2004. Behavior and Ecology. In: The Black Flies (Simuliidae) of North America. Ithaca, New York: Cornell University Press, 71-95.

Applegate JE. 1970. Population Changes in Latent Avian Malaria Infections Associated with Season and Corticosterone Treatment. Journal of Parasitology 56:439-443.

Asghar M., Hasselquist D., Hansson B., Zehtindjiev P., Westerdahl H., Bensch S. 2015. Hidden costs of infection: Chronic malaria accelerates telomere degradation and senescence in wild birds. Science 347:436-438. DOI: 10.1126/science.1261121.

Atkinson CT., Dusek RJ., Woods KL., Iko WM. 2000. Pathogenicity of avian malaria in experimentally-infected Hawaii Amakihi. Journal of Wildlife Diseases 36:197-204. DOI: 10.7589/0090-3558-36.2.197.

Atkinson CT., Lease JK., Drake BM., Shema NP. 2001. Pathogenicity, serological responses, and diagnosis of experimental and natural malarial infections in native hawaiian thrushes. The Condor 103:209-218. DOI: 10.1650/0010-5422(2001)103[0209:psrado]2.0.co;2.

Atkinson CT., Saili KS., Utzurrum RB., Jarvi SI. 2013. Experimental evidence for evolved tolerance to avian malaria in a wild population of low elevation Hawai'i 'Amakihi (Hemignathus virens). EcoHealth 10:366-375. DOI: 10.1007/s10393-013-0899-2.

Beadell JS., Atkins C., Cashion E., Jonker M., Fleischer RC. 2007. Immunological change in a parasite-impoverished environment: Divergent signals from four island taxa. PLoS ONE 2. DOI: 10.1371/journal.pone.0000896.

Bensch S., Åkesson S. 2003. Temporal and Spatial Variation of Hematozoans in Scandinavian Willow Warblers. Journal of Parasitology 89:388-391. DOI: 10.1645/00223395(2003)089[0388:TASVOH]2.0.CO;2.

Bensch S., Hellgren O., Pérez-Tris J. 2009. MalAvi: a public database of malaria parasites and related haemosporidians in avian hosts based on mitochondrial cytochrome $b$ lineages. Molecular Ecology Resources 9:1353-1358. DOI: 10.1111/j.1755-0998.2009.02692.x.

Bensch S., Stjernman M., Hasselquist D., Orjan O., Hannson B., Westerdahl H., Pinheiro RT. 2000. Host specificity in avian blood parasites: a study of Plasmodium and Haemoproteus mitochondrial DNA amplified from birds. Proceedings of the Royal Society B: Biological Sciences 267:1583-1589. DOI: 10.1098/rspb.2000.1181.

Borner J., Pick C., Thiede J., Kolawole OM., Kingsley MT., Schulze J., Cottontail VM., Wellinghausen N., Schmidt-Chanasit J., Bruchhaus I., Burmester T. 2016. Phylogeny of haemosporidian blood parasites revealed by a multi-gene approach. Molecular Phylogenetics and Evolution 94:221-231. DOI: 10.1016/j.ympev.2015.09.003.

Brown CR., Komar N., Quick SB., Sethi RA., Panella NA., Brown MB., Pfe M., Pfeffer M. 2001. Arbovirus infection increases with group size. Proc R Soc Lond B Biol Sci 268:1833-1840. DOI: 10.1098/rspb.2001.1749.

Clark NJ., Clegg SM., Lima MR. 2014. A review of global diversity in avian haemosporidians (Plasmodium and Haemoproteus: Haemosporida): New insights from molecular data. International Journal for Parasitology 44:329-338. DOI: 10.1016/j.ijpara.2014.01.004.

Colwell RK. 2013. EstimateS: Statistical estimation of species richness and shared species from samples. Version 9. User's Guide and application published at: http://purl.oclc.org/estimates.

Colwell RK., Chao A., Gotelli NJ., Lin SY., Mao CX., Chazdon RL., Longino JT. 2012. Models and estimators linking individual-based and sample-based rarefaction, extrapolation and 
432

433

434

435

436

437

438

439

440

441

442

443

444

445

446

447

448

449

450

451

452

453

454

455

456

457

458

459

460

461

462

463

464

465

466

467

468

469

470

471

472

473

474

475

476

477

comparison of assemblages. Journal of Plant Ecology 5:3-21. DOI: 10.1093/jpe/rtr044.

Dobson A., Lafferty KD., Kuris AM., Hechinger RF., Jetz W. 2008. Homage to Linnaeus: How many parasites? How many hosts? Proceedings of the National Academy of Sciences of the United States of America 105:11482-11489. DOI: 10.1073/pnas.0803232105.

Ericson PGP., Zuccon D., Ohlson JI., Johansson US., Alvarenga H., Prum RO. 2006. Higherlevel phylogeny and morphological evolution of tyrant flycatchers, cotingas, manakins, and their allies (Aves: Tyrannida). Molecular Phylogenetics and Evolution 40:471-483. DOI: 10.1016/j.ympev.2006.03.031.

Fecchio A., Lima MR., Silveira P., Braga ÉM., Marini MÂ. 2011. High prevalence of blood parasites in social birds from a neotropical savanna in Brazil. Emu 111:132-138. DOI: 10.1071/MU10063.

Fecchio A., Pinheiro R., Felix G., Faria IP., Pinho JB., Lacorte GA., Braga EM., Farias IP., Aleixo A., Tkach V V., Collins MD., Bell JA., Weckstein JD. 2017. Host community similarity and geography shape the diversity and distribution of haemosporidian parasites in Amazonian birds. Ecography. DOI: 10.1111/ecog.03058.

Galen SC., Witt CC. 2014. Diverse avian malaria and other haemosporidian parasites in Andean house wrens: Evidence for regional co-diversification by host-switching. Journal of Avian Biology 45:374-386. DOI: 10.1111/jav.00375.

Garamszegi LZ. 2011. Climate change increases the risk of malaria in birds. Global Change Biology 17:1751-1759. DOI: 10.1111/j.1365-2486.2010.02346.x.

Garvin MC., Schoech SJ. 2006. Hormone levels and infection of Haemoproteus danilewskyi in free-ranging blue jays (Cyanocitta cristata). The Journal of parasitology 92:659-662. DOI: 10.1645/GE-759R.1.

Hellgren O., Waldenström J., Bensch S. 2004. a New Pcr Assay for Simultaneous Studies of Leucocytozoon, Plasmodium, and Haemoproteus From Avian Blood. Journal of Parasitology 90:797-802. DOI: 10.1645/GE-184R1.

Hellgren O., Waldenström J., Peréz-Tris J., Szöll Ösi E., Hasselquist D., Krizanauskiene A., Ottosson U., Bensch S. 2007. Detecting shifts of transmission areas in avian blood parasites - A phylogenetic approach. Molecular Ecology 16:1281-1290. DOI: 10.1111/j.1365294X.2007.03227.x.

Jarvis A., Reuter HI., Nelson A., Guevara E. 2008. Hole-filled seamless SRTM data V4. International Centre for Tropical Agriculture (CIAT):available from http://srtm.csi.cgiar.org.

Jetz W., Thomas GH., Joy JB., Hartmann K., Mooers AO. 2012. The global diversity of birds in space and time. Nature 491:444-448. DOI: 10.1038/nature11631.

Jetz W., Thomas GH., Joy JB., Redding DW., Hartmann K., Mooers AO. 2014. Global Distribution and Conservation of Evolutionary Distinctness in Birds. Current Biology 24:919-930. DOI: 10.1016/j.cub.2014.03.011.

Kearse M., Moir R., Wilson A., Stones-Havas S., Cheung M., Sturrock S., Buxton S., Cooper A., Markowitz S., Duran C., Thierer T., Ashton B., Meintjes P., Drummond A. 2012. Geneious Basic: An integrated and extendable desktop software platform for the organization and analysis of sequence data. Bioinformatics 28:1647-1649. DOI: 10.1093/bioinformatics/bts 199.

Knowles SCL., Palinauskas V., Sheldon BC. 2010. Chronic malaria infections increase family inequalities and reduce parental fitness: experimental evidence from a wild bird population. Journal of Evolutionary Biology 23:557-569. DOI: 10.1111/j.1420-9101.2009.01920.x. 
478

479

480

481

482

483

484

485

486

487

488

489

490

491

492

493

494

495

496

497

498

499

500

501

502

503

504

505

506

507

508

509

510

511

512

513

514

515

516

517

518

519

520

521

522

523

Kulma K., Low M., Bensch S., Qvarnström A. 2013. Malaria infections reinforce competitive asymmetry between two Ficedula flycatchers in a recent contact zone. Molecular Ecology 22:4591-4601. DOI: 10.1111/mec.12409.

Lachish S., Knowles SCL., Alves R., Wood MJ., Sheldon BC. 2011. Infection dynamics of endemic malaria in a wild bird population: Parasite species-dependent drivers of spatial and temporal variation in transmission rates. Journal of Animal Ecology 80:1207-1216. DOI: 10.1111/j.1365-2656.2011.01893.x.

LaPointe DA., Goff ML., Atkinson CT. 2010. Thermal constraints to the sporogonic development and altitudinal distribution of avian malaria Plasmodium relictum in Hawai'i. The Journal of parasitology 96:318-324. DOI: 10.1645/GE-2290.1.

Levin II., Zwiers P., Deem SL., Geest EA., Higashiguchi JM., Iezhova TA., Jiménez-Uzcátegui G., Kim DH., Morton JP., Perlut NG., Renfrew RB., Sari EHR., Valkiunas G., Parker PG. 2013. Multiple Lineages of Avian Malaria Parasites (Plasmodium) in the Galapagos Islands and Evidence for Arrival via Migratory Birds. Conservation Biology 27:1366-1377. DOI: 10.1111/cobi.12127.

Loiseau C., Harrigan RJ., Cornel AJ., Guers SL., Dodge M., Marzec T., Carlson JS., Seppi B., Sehgal RNM. 2012. First Evidence and Predictions of Plasmodium Transmission in Alaskan Bird Populations. PLoS ONE 7:7-11. DOI: 10.1371/journal.pone.0044729.

Lutz HL., Hochachka WM., Engel JI., Bell JA., Tkach V V., Bates JM., Hackett SJ., Weckstein JD. 2015. Parasite prevalence corresponds to host life history in a diverse assemblage of afrotropical birds and haemosporidian parasites. PLOS ONE 10. DOI: 10.1371/journal.pone.0121254.

Martinsen ES., Blumberg BJ., Eisen RJ., Schall JJ. 2008. Avian hemosporidian parasites from northern California oak woodland and chaparral habitats. Journal of wildlife diseases 44:260-268. DOI: 10.7589/0090-3558-44.2.260.

Medeiros MCI., Ricklefs RE., Brawn JD., Hamer GL. 2015. Plasmodium prevalence across avian host species is positively associated with exposure to mosquito vectors. Parasitology 142:1612-1620. DOI: 10.1017/S0031182015001183.

Moens MAJ., Valkiūnas G., Paca A., Bonaccorso E., Aguirre N., Pérez-Tris J., Cotter S. 2016. Parasite specialization in a unique habitat: hummingbirds as reservoirs of generalist blood parasites of Andean birds. Journal of Animal Ecology 85:1234-1245. DOI: 10.1111/13652656.12550.

Moyle RG., Oliveros CH., Andersen MJ., Hosner PA., Benz BW., Manthey JD., Travers SL., Brown RM., Faircloth BC. 2016. Tectonic collision and uplift of Wallacea triggered the global songbird radiation. Nature Communications 7:1-7. DOI: 10.1038/ncomms12709.

Oakgrove KS., Harrigan RJ., Loiseau C., Guers S., Seppi B., Sehgal RNM. 2014. Distribution, diversity and drivers of blood-borne parasite co-infections in Alaskan bird populations. International Journal for Parasitology 44:717-727. DOI: 10.1016/j.ijpara.2014.04.011.

Outlaw DC., Ricklefs RE. 2014. Species limits in avian malaria parasites (Haemosporida): how to move forward in the molecular era. Parasitology 141:1223-32. DOI: $10.1017 / \mathrm{S} 0031182014000560$.

Poulin R. 2014. Parasite biodiversity revisited: Frontiers and constraints. International Journal for Parasitology 44:581-589. DOI: 10.1016/j.ijpara.2014.02.003.

Ricklefs RE., Fallon SM. 2002. Diversification and host switching in avian malaria parasites. Proceedings of the Royal Society B: Biological Sciences 269:885-892. DOI: 10.1098/rspb.2001.1940. 
524 Ricklefs RE., Outlaw DC., Svensson-Coelho M., Medeiros MCI., Ellis VA., Latta S. 2014.

525

526

527

528

529

530

531

532

533

534

535

536

537

538

539

540

541

542

543

544

545

546

547

548

549

550

551

552

553

554

555

556

557

558

559

560

561

562

563

564

565

566

567

568

569

Species formation by host shifting in avian malaria parasites. Proceedings of the National Academy of Sciences of the United States of America 111:14816-21. DOI: 10.1073/pnas.1416356111.

Ricklefs RE., Swanson BL., Fallon SM., Martinez-Abrain A., Scheuerlein A., Gray J., Latta S. 2005. Community Relationships of Avian Malaria Parasites in Southern Missouri. Ecological Monographs 75:543-559. DOI: 10.1890/04-1820.

van Riper C., van Riper SG., Goff ML., Laird M. 1986. The Epizootiology and Ecological Significance of Malaria in Hawaiian Land Birds. Ecological Monographs 56:327-344. DOI: $10.2307 / 1942550$.

Robinet C., Roques A. 2010. Direct impacts of recent climate warming on insect populations. Integrative Zoology 5:132-142. DOI: 10.1111/j.1749-4877.2010.00196.x.

Romero LM. 2002. Seasonal changes in plasma glucocorticoid concentrations in free-living vertebrates. General and Comparative Endocrinology 128:1-24. DOI: 10.1016/S00166480(02)00064-3.

Scott TW., McLean RG., Bruce Francy D., Card CS. 1983. A Simulation Model for the VectorHost Transmission System of a Mosquito-Borne Avian Virus, Turlock (Bunyaviridae) 1. Journal of Medical Entomology 20:625-640.

Silva-Iturriza A., Ketmaier V., Tiedemann R. 2012. Prevalence of avian haemosporidian parasites and their host fidelity in the central Philippine islands. Parasitology International 61:650-657. DOI: 10.1016/j.parint.2012.07.003.

Stamatakis A. 2014. RAxML version 8: a tool for phylogenetic analysis and post-analysis of large phylogenies. Bioinformatics 30:1312-1313. DOI: 10.1093/bioinformatics/btu033.

Svensson-Coelho M., Blake JGJG., Loiselle B a., Penrose a. SAS., Parker PG., Ricklefs RE. 2013. Diversity, Prevalence, and Host Specificity of Avian Plasmodium and Haemoproteus in a Western Amazon Assemblage. DOI: 10.1525/om.2013.76.1.1.1.

Svensson-Coelho M., Silva GT., Santos SS., Miranda LS., Araujo-Silva LE., Ricklefs RE., Miyaki CY., Maldonado-Coelho M. 2016. Lower Detection Probability of Avian Plasmodium in Blood Compared to Other Tissues. Journal of Parasitology 102:559-561. DOI: $10.1645 / 16-8$.

Valkiunas G. 2005. Avian malaria parasites and other haemosporidia. Boca Raton, Florida, USA: CRC Press.

Valkiūnas G., Bairlein F., Iezhova TA., Dolnik O V. 2004. Factors affecting the relapse of Haemoproteus belopolskyi infections and the parasitaemia of Trypanosoma spp. in a naturally infected European songbird, the blackcap, Sylvia atricapilla. Parasitology Research 93:218-222. DOI: 10.1007/s00436-004-1071-2.

Valkiŭnas G., Iezhova T a., Križanauskiené A., Palinauskas V., Sehgal RNM., Bensch S. 2008. A comparative analysis of microscopy and PCR-based detection methods for blood parasites. The Journal of Parasitology 94:1395-401. DOI: 10.1645/GE-1570.1.

Valkiunas G., Kazlauskiene R., Bernotiene R., Palinauskas V., Iezhova TA. 2013. Abortive longlasting sporogony of two Haemoproteus species (Haemosporida, Haemoproteidae) in the mosquito Ochlerotatus cantans, with perspectives on haemosporidian vector research. Parasitology Research 112:2159-2169. DOI: 10.1007/s00436-013-3375-6.

Waldenström J., Bensch S., Hasselquist D., Östman Ö. 2004. A New Nested Polymerase Chain Reaction Method Very Efficient in Detecting Plasmodium and Haemoproteus Infections from Avian Blood A New Nested Polymerase Chain Reaction Method Very Efficient in 
570 Detecting Plasmodium and Haemoproteus Infections From Avian B. Journal of 571 Parasitology 90:191-194. DOI: 10.1645/GE-3221RN.

572 Waldenström J., Bensch S., Kiboi S., Hasselquist D., Ottosson U. 2002. Cross-species infection 573 of blood parasites between resident. Molecular Ecology 11:1545-1554.

Walther EL., Carlson JS., Cornel A., Morris BK., Sehgal RNM. 2016. First molecular study of prevalence and diversity of avian haemosporidia in a central California songbird community. Journal of Ornithology 157:549-564. DOI: 10.1007/s10336-015-1301-7.

Warner RE. 1968. The role of introduced diseases in the extinction of the endemic Hawaiian avifauna. The Condor 70:101-120. DOI: 10.2307/1365954.

Yohannes M., Haile M., Ghebreyesus TA., Witten KH., Getachew A., Byass P., Lindsay SW. 2005. Can source reduction of mosquito larval habitat reduce malaria transmission in Tigray, Ethiopia? Tropical Medicine and International Health 10:1274-1285. DOI: 10.1111/j.1365-3156.2005.01512.x. 
585 Table 1 Positive infections identified from microscopy, PCR, and both methods combined. Total

586 screened indicates the number of individual birds screened by each method. Of those screened,

587 the number and proportion of individuals that were positive are reported. Detection rates were

588 higher for PCR, although three samples were positively identified using microscopy but not 589 PCR.

590

591

592

\begin{tabular}{llccc} 
Method & $\begin{array}{l}\text { Total } \\
\text { screened }\end{array}$ & $\begin{array}{c}\text { Haemoproteus/Plasmodium } \\
\text { No. positive (\%) }\end{array}$ & $\begin{array}{c}\text { Leucocytozoon } \\
\text { No. positive (\%) }\end{array}$ & $\begin{array}{c}\text { Overall } \\
\text { No. positive (\%) }\end{array}$ \\
\hline Microscopy & 168 & $40(23.8 \%)$ & $7(4.2 \%)$ & $43(25.6 \%)$ \\
PCR & 186 & $55(29.6 \%)$ & $25(13.4 \%)$ & $65(34.9 \%)$ \\
Combined & 186 & $58(31.2 \%)$ & $25(13.4 \%)$ & $68(36.6 \%)$ \\
\hline
\end{tabular}


594 Figure 1 Map of study areas and 2016 sampling localities. Fieldwork was conducted in three

595 sites located in piñon-juniper and ponderosa pine woodland habitats (elevational range: $2150-$

5962460 meters). The number of infections detected by PCR and sequencing at each site for

597 Haemoproteus $(\mathrm{H})$, Plasmodium (P), and Leucocytozoon (L) is shown. Note that two infections

598 from El Malpais could not be assigned to $\mathrm{H}$ or $\mathrm{P}$ because of poor sequence quality, resulting in

59981 infections shown. Elevation is based on the SRTM Digital Elevation Database (Jarvis et al., 600 2008).

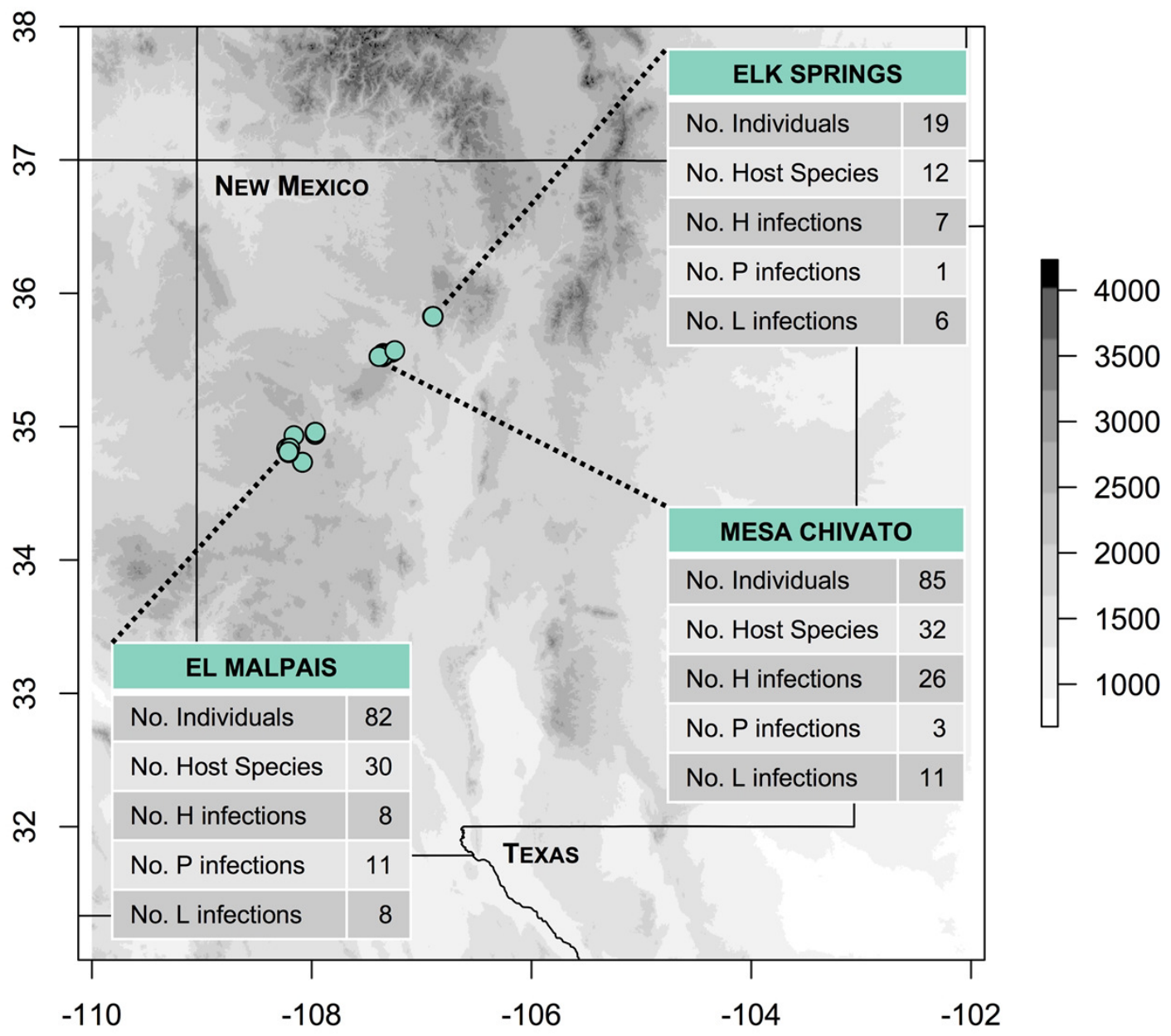

601

602

603

604 
605 Figure 2 Phylogeny of haemosporidian haplotypes found in New Mexico birds. Columns represent host clades (left) and host species

606 (right). Dotted line indicates non-monophyly of non-passerines, and clade names are based on the names and topology from Moyle et

607 al. (2016). Host species phylogeny was generated from BirdTree.org and the colors of host clade branches correspond to host species

608 in each clade. Bar plots depict the combined infection rate (number of infections divided by number of birds screened) for each

609 parasite genus: Haemoproteus (turquoise), Plasmodium (dark brown), Leucocytozoon (light brown). Stars indicate novel

610 haemosporidian haplotypes. The parasite phylogeny was estimated in RAxML and branch labels indicate bootstrap values. The table

611 is shaded to indicate which clade/species was infected with each haplotype. The number of infections sequenced for each haplotype

612 and bird clade/species is shown, representing a total of 77 sequenced infections. 


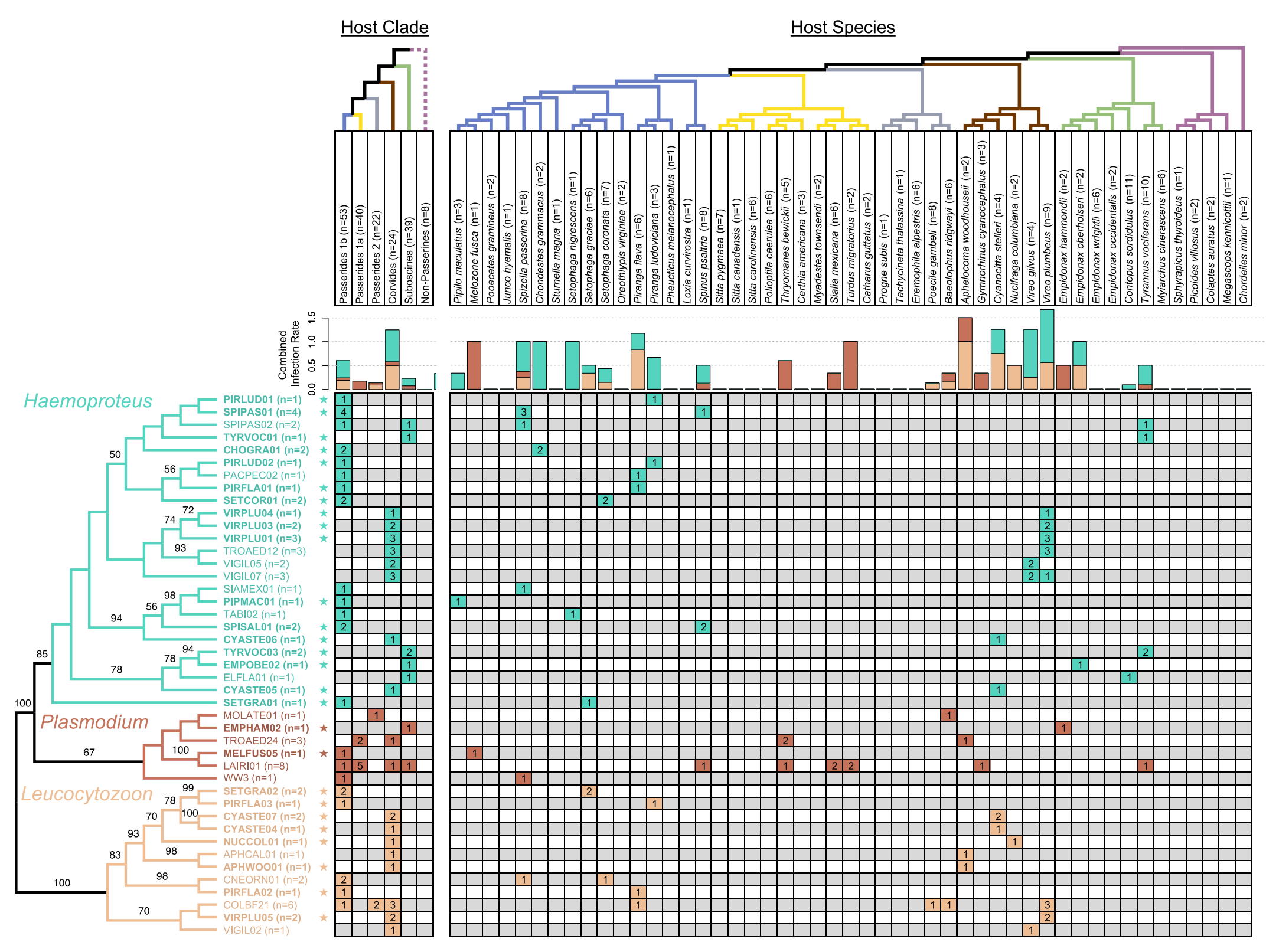


614 Figure 3 Estimate of haemosporidian lineage diversity in northern New Mexico based on

615 EstimateS rarefaction and extrapolation using 77 avian haemosporidian infections and 43 distinct

616 haplotypes. The point indicates the reference sample, solid line the rarefaction, and dotted line

617 the extrapolation. The analysis suggests that sampling approximately 240 total infections would

618 capture $>95 \%$ of the haemosporidian lineage diversity in this community. The total haplotype

619 richness is estimated to be 70 (95\% CI: 43-98).

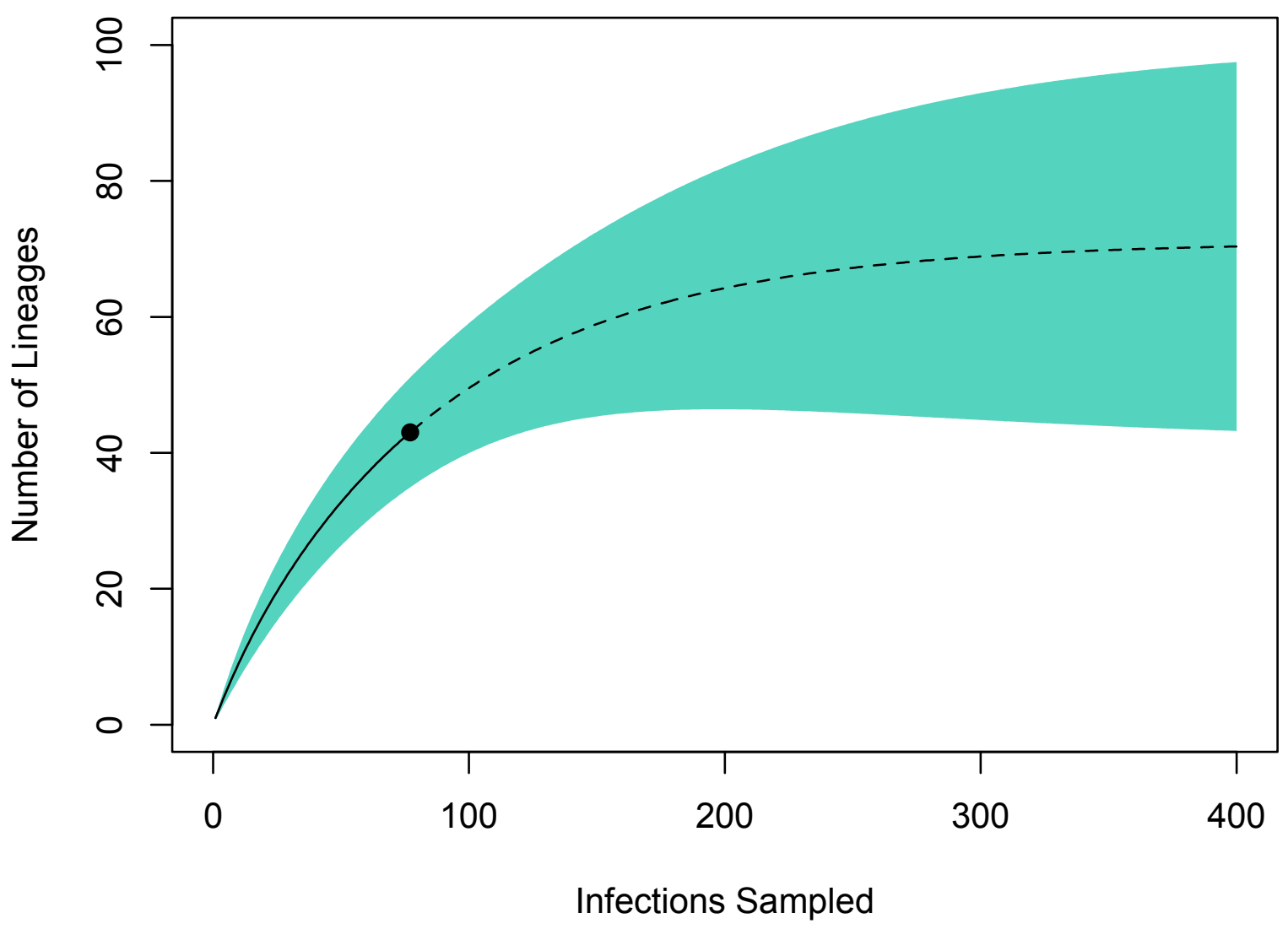

620 